\title{
The effect of the lower instrumented vertebra (LIV) on pain and quality of life in patients surgically treated for an idiopathic scoliosis
}

J Sanchez-Raya*, J Bago

From 8th International Conference on Conservative Management of Spinal Deformities and SOSORT 2011

Annual Meeting

Barcelona, Spain. 19-21 May 2011

\section{Purpose}

The objectives of the study are: 1) to measure lumbar spine mobility and analyze the influence of the lower instrumented vertebra (LIV) in patients treated surgically for idiopathic scoliosis, and 2) to determine the correlation between the LIV, lumbar mobility, pain, and quality of life.

\section{Materials and methods}

40 patients (36 women, 4 men) were included (mean age 27 years); average time since surgery was 135 months. The mean residual major curve Cobb angle was $35.4^{\circ}$. Lumbar mobility was measured during forward and lateral lumbar flexions using a dual digital inclinometer.

Patients fulfilled the SRS22 Questionnaire and the Quality of Life in Spine Deformities Profile to estimate the perceived sensation of rigidity. Additionally, they rated the pain in the low back area.

\section{Results}

Lumbar mobility decreased in relation to the LIV. There was no correlation between lumbar range of motion and pain. The LIV do not correlated with the sensation of rigidity. The sensation of rigidity correlated both with SRS22 pain scale and the intensity of low back pain.

Health-related quality of life was moderately correlated with the LIV and lumbar mobility.

\section{Conclusions}

The LIV has an influence on lumbar mobility. The intensity of low back pain is mild in these patients and is not related to the LIV nor to lumbar mobility. The subjective perception of rigidity does not correspond to the loss of

Hospital Vall d'Hebron, Barcelona, Spain lumbar mobility, but rather, is determined by the coexistence of pain. The LIV has a moderate effect on the global quality of life.

Published: 27 January 2012

doi:10.1186/1748-7161-7-S1-P16

Cite this article as: Sanchez-Raya and Bago: The effect of the lower instrumented vertebra (LIV) on pain and quality of life in patients surgically treated for an idiopathic scoliosis. Scoliosis 2012 7(Suppl 1):P16.
Submit your next manuscript to BioMed Central and take full advantage of:

- Convenient online submission

- Thorough peer review

- No space constraints or color figure charges

- Immediate publication on acceptance

- Inclusion in PubMed, CAS, Scopus and Google Scholar

- Research which is freely available for redistribution
C Biomed Central 